\title{
Infarction of the human liver
}

\author{
R. CARROLL \\ From the Department of Pathology, University of Liverpool
}

SYNOPSIS The rarity of hepatic infarction in the human being is commonly explained as due to the double blood supply via the hepatic artery and the portal vein. This explanation cannot be accepted, because, if the arterial blood supply alone is arrested the portal blood supply does not protect the liver from infarction. The factor of importance is that the arterial blood supply comes by three different routes and it is difficult to obstruct these collateral supplies simultaneously. Infarction of the liver can be caused by thrombosis or ligation of the main hepatic artery between the origin of the right gastric artery and the hilum of the liver, but the more common causes are infected emboli or polyarteritis nodosa; these presumably interfere not only with the main arterial supply but also with some of the collateral arterial supply.

Infarction of the human liver is rare and its aetiology is poorly understood. The rarity of the lesion has been attributed in the past either to the protective effect of the dual blood supply to the liver by the hepatic artery and the portal vein (Losner, Volk, and Jacobi, 1950) or to the anatomical arrangement of the hepatic artery (Pass, 1935). In view of the findings in some recent experimental work (Carroll, 1963) it seems probable that the importance of these factors is subsidiary to that of the collateral arterial circulation. Some authors think that occlusion of the hepatic artery is not the sole cause of infarction of the liver, and that occlusion of the portal vein may lead to infarction if it is associated with some other factor tending to produce anoxaemia (Woolling, Baggenstoss, and Weir, 1951).

\section{AETIOLOGICAL FACTORS}

The causative factors in the 19 cases of hepatic infarction in the present series are summarized in the Table. The four cases of thrombosis of the hepatic artery due to unknown cause include two cases in

TA B LE

CASES OF INFARCTION OF THE LIVER

\begin{tabular}{llc} 
Cause of Infarction & Secondary to & Number \\
\hline Polyarteritis nodosa & & 5 \\
Embolism of hepatic artery & Acute bacterial endocarditis & 4 \\
& Thrombus in left ventricle & 1 \\
& Unknown cause & 2 \\
Thrombosis of hepatic artery & Carcinoma of bile duct & 1 \\
& Metastatic carcinoma of liver & 2 \\
& Unknown cause & 4
\end{tabular}

Received for publication 17 November 1962. which there were thrombi in many of the visceral arteries, one case of thrombosis of the coeliac axis in a male of 32, and one case of thrombosis of the aorta in a male child 15 days old.

\section{PATHOLOGICAL FINDINGS}

MACROSCOPIC APPEARANCES The majority of the infarcts were situated in the right lobe of the liver and consisted of localized areas varying from a few millimetres up to about $5 \mathrm{~cm}$. in diameter, though there was one case with an enormous infarct which involved the whole of the left lobe of the liver and the lower half of the right lobe. The infarcts were usually pale in colour and some of them had a zone of congestion at the edge. Most were deep in the substance of the liver but the more superficial were separated from the surface by a thin band of normal liver tissue.

In five of the cases of thrombosis of the hepatic artery proximal to the hilum of the liver, the vessels were carefully examined. The thrombus was found in the right hepatic artery in four of these cases and also in the main hepatic artery in the fifth case. These thrombi always extended up to the infarct in the liver substance.

In two of the cases of embolism there was secondary thrombosis in the hepatic artery proximal to the embolus and also extending distally from the embolus as far as the infarct.

MICROSCOPIC APPEARANCES The infarcts observed macroscopically are usually found on microscopic examination to consist of a number of smaller components which will be described according to 


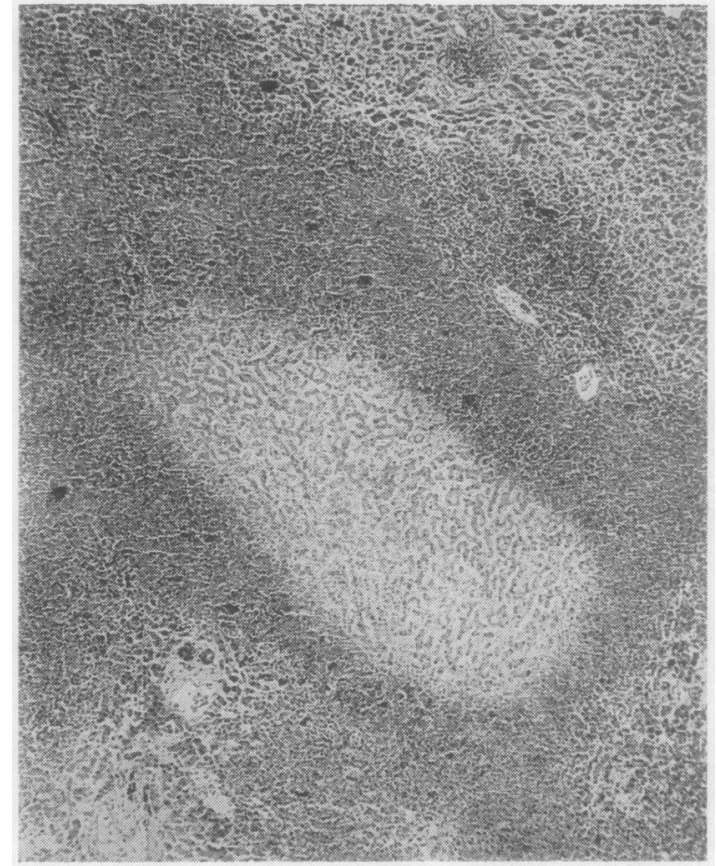

FIG. 1

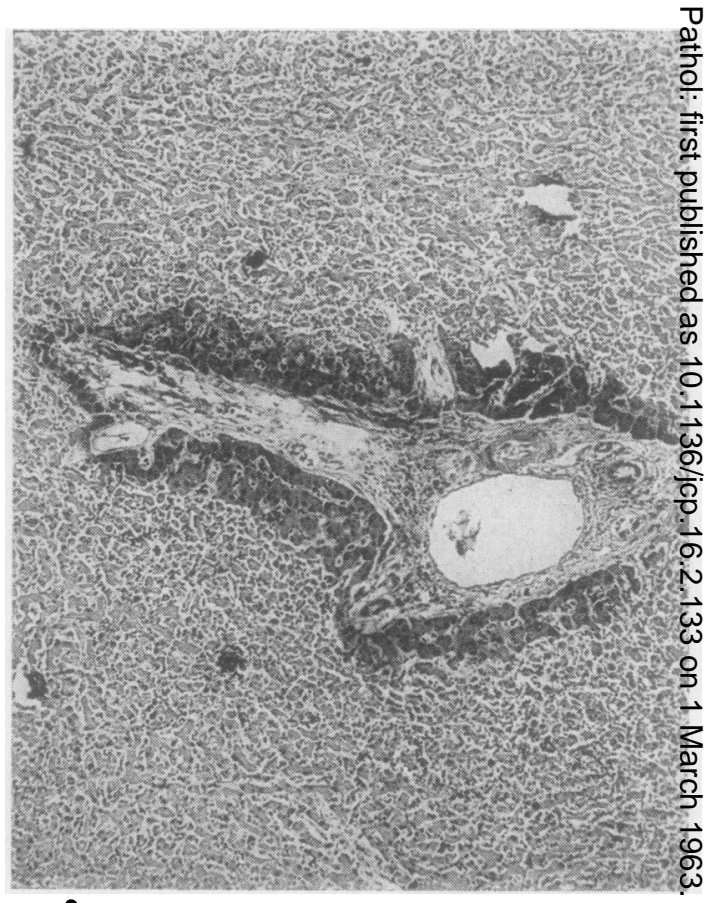

FIG. 2

FIG. 1. A large infarct approximately two to three days old. The pale area is the central dead area. The polymorph zon is developing around the edge of this area, and outside the polymorph zone is the peripheral dead zone and the partiat survival zone. These latter zones cannot be distinguished from each other in the photograph. Haematoxylin and eosin $\times 40_{2}^{\circ}$ FIG. 2. A surviving portal tract surrounded by a zone of undamaged liver cells. The remainder of the liver tissue infarcted. Haematoxylin and eosin $\times 65$.

their size, beginning with the largest and finishing with the smallest.

The largest components (Fig. 1) are infarcts 3 to $15 \mathrm{~mm}$. in diameter which have a central dead area surrounded by four distinct marginal zones (Sheehan and Davis, 1958).

The central dead area varies from $0.5 \mathrm{~mm}$. up to $10 \mathrm{~mm}$. in diameter. In this area the liver cells are usually normal in size and have a pale granular cytoplasm. The nuclei of these cells are fading or, in the older lesions, have faded completely. There are no red corpuscles or polymorphonuclear leucocytes in the sinusoids. The Kupffer cells and the structures in the portal tract have undergone the same changes as the liver cells. The vessels are either empty or have a very fine web of fibrin in the lumen. The changes in the structures in the central dead area are related to the period of time that has elapsed since the initial ischaemia; from the study of experimental infarction the infarcts in the present series range from about three days old in some cases up to a couple of weeks old in other cases.

In the cases at about three days old there is a polymorph zone, about $0.1 \mathrm{~mm}$. in depth. In the cases where the infarct is clearly in its second week the polymorph zone is represented only by a thip band of basophil debris.

The peripheral dead zone is easily identifiable in infarcts three days old. It is approximately $0.2 \mathrm{~mm}$ in depth and the changes in the liver cells are similar to those in the central dead area. In the second weel this zone is difficult to differentiate from the adjoin ing partial survival zone, as at this stage all the liver. cells external to the polymorph zone have the sams appearance. They are shrunken, their cytoplasm is eosinophilic, and their nuclei are pyknotic op karyolytic. Red corpuscles have reappeared in the sinusoids. The Kupffer cells are alive and in man£ cases show proliferation. Many of the portal tracto are surrounded by a thin band of live liver cells (Fig. 2). There is a proliferation of bile ducts in this zone, usually more marked in the portal tracts which are not surrounded by live liver cells. There are no thrombi in the vessels in the portal tracts.

In the live margin zone external to the partia survival zone there is an occasional vacuolated live 


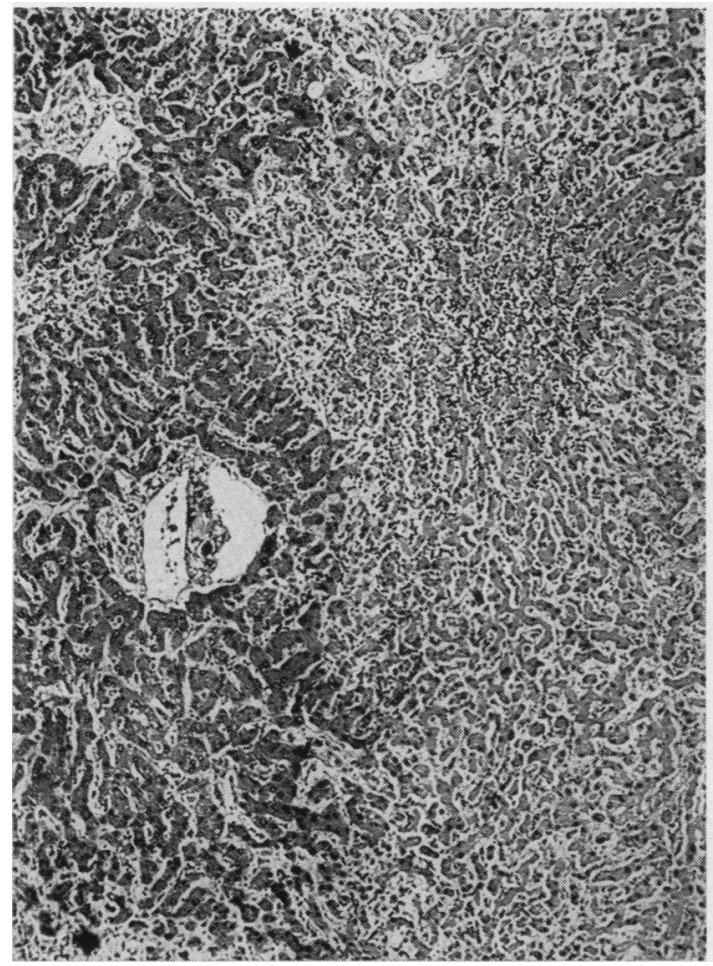

FIG. 3. Junction of normal liver tissue with a small infarct. The liver cells in the infarct have shrunken eosinophilic cytoplasm with pyknotic or karyolytic nuclei. There are some red corpuscles in the sinusoids. Haematoxylin and eosin $\times 65$.

cell at three to four days but no mitotic activity has been noticed in the liver cells at any stage.

Intermediate sized infarcts, $2 \mathrm{~mm}$. in diameter, are too small to have a central dead area or polymorph zone. Small infarcts, $0.5 \mathrm{~mm}$. in diameter, are formed entirely of partial survival zone (Fig. 3). The histological appearances of the liver cells and the other structures in the zones of the intermediate and small infarcts are similar to those in the corresponding zones of the large infarcts. The histology of the infarcts is also usually similar irrespective of the cause. However, when sepsis is superadded, there are usually a large number of polymorphonuclear leucocytes and bacteria scattered throughout the small and the intermediate infarcts and the marginal zones of the large infarcts. Bacteria are also found in the central dead area of the large infarcts but the polymorphs do not penetrate beyond the polymorph zone.

\section{DISCUSSION}

The initial problem concerns the cause of infarction. There is no doubt at all that the infarction is due purely to arterial obstruction. Parker (1955) has shown in man, and Carroll (1963) in the rabbit, that ligation of the hepatic artery alone with a free flow along the portal vein, results in infarction of the related parts of the liver. Obstruction of the portal vein alone does not produce infarction of the liver in man (Child, 1954) or in the rabbit (Carroll, 1963).

The second problem is why infarction occurs so very rarely in the liver. The old explanation is that the double blood supply by the portal vein and the hepatic artery protects the liver from infarction but this theory must be abandoned in view of the evidence given in the previous paragraph. The more satisfactory explanation depends on the fact that the arterial blood supply of the liver has various collateral pathways so that complete arrest of the arterial blood flow is not easily produced. The prehilar part of the hepatic artery has anastomotic connexions with the coeliac axis and superior mesenteric arteries by way of its gastroduodenal and right gastric branches. When the hepatic artery subdivides inside the liver it produces not only large branches but also numerous smaller collateral branches which run along the portal tracts and provide an additional blood supply to the same areas of liver which are fed by the main branches. In man and dog (Segall, 1923; Jefferson, Hassan, Popper, and Necheles, 1956), but not in the rabbit (Carroll, 1963), there are very important anastomoses in the upper part of the liver between branches of the diaphragmatic arteries and small branches of the hepatic artery.

The third problem is to explain why, despite this collateral arterial supply, infarction does occasionally occur in the liver. There are four groups of causes.

1 SURGICAL LIGATURE The hepatic artery is sometimes ligatured deliberately, as, for instance, in the treatment of aneurysm of the hepatic artery, or occasionally accidentally at cholecystectomy. The literature on this subject has been analysed by Graham and Cannell (1933) who concluded, often on clinical grounds only, that infarction of parts of the liver occurred in 14 out of 28 cases where the artery was tied. Lund, Stewart, and Lieber (1935), in an analysis of the literature, accepted only six of these cases as authentic. Further reports of acceptable cases have been given more recently: six cases by Woolling et al. (1951) and six cases by Parker (1955).

The point of chief importance which emerges from these accounts is that if the main hepatic artery is ligated before it gives off its right gastric branch no infarction occurs in the liver. This is because the anastomoses allow a reverse flow along the right gastric artery, and this provides a satisfactory arterial circulation up the peripheral part of the hepatic artery. 
On the other hand, if the hepatic artery is ligated distal to the origin of the right gastric artery, there is a much higher incidence of infarction of the liver.

2 BLAND EMBOLISM The results may be expected to differ according to the site of arrest of the embolus. In the case of the extrahepatic portion of the hepatic artery the evidence in the last paragraph suggests that embolism of the artery in its first part, i.e., up to the origin of the right gastric artery, would not cause infarction, but that embolism of the distal part, i.e., from the origin of the right gastric artery to the hilum of the liver, would produce infarcts. The effect of arrest of emboli in the branches of the hepatic artery inside the liver would depend on the extent of the intrahepatic collateral blood flow. In fact infarcts due to bland embolism are extremely rare. There is only one case in the present series. Pass (1935) analysed the literature and found eight cases. Losner et al. (1950) found two more cases in the literature, and Parker (1955) has recorded one further case. In these few cases the emboli came from the vegetations of rheumatic heart disease, from mural thrombus in the chambers of the left heart, and from thrombus in aortic aneurysms.

Various authors appear to assume that, because infarction does not occur in the liver, emboli do not go up the hepatic artery, and they then proceed to explain why emboli do not go up. For example, Pass (1935) considered that the important factor in preventing embolism of the hepatic artery was the acute angle at which this artery arose from the coeliac axis. In fact there is no available evidence about the distribution of emboli in human beings, but there seems to be no good reason why emboli should not go up the hepatic artery just as frequently as they go along the splenic artery.

3 LOCAL LESIONS OF SMALL VESSELS IN LIVER The great majority of infarcts are due to septic embolism or polyarteritis nodosa in the branches of the hepatic artery in the liver. These lesions are of the type which produces an inflammatory reaction in the adjacent tissues and this could also involve the collateral arterial vessels which run close to the main artery in the portal tract.

Infected embolism There are four cases of infected emboli from bacterial endocarditis among the 19 liver infarcts of the present series. This is roughly the same incidence as has been reported in the literature. Pass (1935) found from an analysis of the literature that 13 out of 52 cases of hepatic infarction had bacterial endocarditis. Losner et al. (1950) analysed the literature of the next 15 years and found that five out of 18 hepatic infarcts were due to the same cause. Parker (1955) reported that four of the 18 infarcts in his series were due to bacteria endocarditis. It is not clear whether these infected? emboli had given rise to mycotic aneurysms which had subsequently thrombosed or whether they had? produced a periarteritis.

Polyarteritis nodosa In the earlier literature polyarteritis nodosa is, understandably enough, nop recorded as a cause of infarction. There are fives cases in the present group. Pass (1935) in his analysis of the literature considered that 22 out of 52 cases were due to polyarteritis nodosa. Losner $e \overrightarrow{t_{\omega}}$ al. (1950) found a further four cases in the literature. Parker (1955) considered that this disease was the cause of arterial occlusion in five out of his 18 cases of hepatic infarction. It is likely that the periarteritisiv would involve not only the main artery but also thew smaller collateral arteries in the portal tract around ${ }_{0}^{\omega}$ In addition it may possibly lead to thrombosis of the neighbouring portal vein but, for reasons given $\vec{\zeta}$ previously, this cannot be accepted as playing anyou significant part in causing the infarction.

4 THROMBOsIS Thrombosis can occur in relationo to mycotic or other aneurysms or to polyarteritis ${ }^{\omega}$ nodosa, or on a basis of embolism, but in mose cases the thrombosis of the hepatic artery appears tos be idiopathic. In seven cases of the present serieso there was thrombosis of the hepatic artery in theo vulnerable site, i.e., between the origin of the right gastric artery and the hilum of the liver. These hao produced infarction of part of the affected lobes 3 though the collateral circulation from the diaphrag matic vessels had protected other parts. The present. incidence is rather higher than that recorded by other workers: Lund et al. (1935) reported two cases, Pass (1935) found eight cases in the literature, Losner et al (1950) added three more cases from the literature, and Parker (1955) recorded a further two cases.

I wish to thank Professor H. L. Sheehan for his interes? and advice during the preparation of this paper.

\section{REFERENCES}

Carroll, R. (1963). J. Path. Bact., In pres;.

Child, C. G. (1954). The Hepatic Circulation and Portal Hypertension Pp. 176, and 285-310. Saunders, Philadelphia and London.

Graham, R. R., and Cannell, D. (1933). Brit. J. Surg., 20, 566.

Jefferson, N. C., Hassan, M. I., Popper, H. L., and Necheles, $\mathbf{H}_{C O}$ (1956). Amer. J. Physiol., 184, 589.

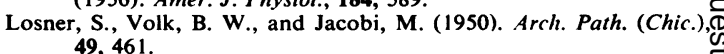

Lund, H., Stewart, H. L., and Lieber, M. M. (1935). Amer. J. Path., 11, 157.

Parker, R. G. F. (1955). J. Path. Bact., 70, 521.

Pass, I. J. (1935). Amer, J. Path., 11, 503.

Segall, H. N. (1923). Surg. Gynec. Obstet, 37, 152

Sheehan, H. L., and Davis, J. C. (1958). J. Path. Bact., 76, 569.

Woolling, K. R., Baggenstoss, A. H., and Weir, J. F. (1951). Gastroenterology, 17, 479. 